\title{
ChemComm
}

RSCPublishing

Cite this: Chem. Commun., 2013, 49, 2061

Received 30th November 2012, Accepted 22nd January 2013

DOI: $10.1039 /$ c3cc38607d

\section{(S)-Selective MenD variants from Escherichia coli provide access to new functionalized chiral $\alpha$-hydroxy ketones $\dagger$}

\author{
Robert Westphal, ${ }^{\text {a }}$ Simon Waltzer, ${ }^{\text {b }}$ Ursula Mackfeld, ${ }^{a}$ Michael Widmann, ${ }^{c}$ \\ Jürgen Pleiss, ${ }^{c}$ Maryam Beigi, ${ }^{b}$ Michael Müller, ${ }^{b}$ Dörte Rother ${ }^{a}$ and Martina Pohl*a
}

www.rsc.org/chemcomm

We report the first rationally designed (S)-selective MenD from $E$. coli for the synthesis of functionalized $\alpha$-hydroxy ketones. By mutation of two amino acids in the active site stereoselectivity of the $(R)$-selective EcMenD (ee $>93 \%$ ) was inverted giving access to (S)-5-hydroxy-4-oxo-5-phenylpentanoate derivatives with stereoselectivities up to $97 \%$ ee.

Optically active $\alpha$-oxyfunctionalized carbonyl compounds are valuable synthetic building blocks in preparative organic chemistry. ${ }^{1}$ Among them, $\alpha$-hydroxy ketones are of particular value for the pharmaceutical as well as the fine chemistry sector. ${ }^{2}$ In addition, $\alpha$-hydroxy ketones are putative precursors of 2-amino alcohols, or 1,2-diols, among others. ${ }^{3,4}$ Various non-enzymatic routes to chiral $\alpha$-hydroxy ketones have been reported including organocatalytic strategies. ${ }^{5,6}$ However, high stereoselectivities are rare. Furthermore, most of the syntheses require several steps, which impair the overall yields. ${ }^{2}$

Thiamine diphosphate (ThDP)-dependent enzymes are well known for their catalytic potential to form various $\alpha$-hydroxy ketones. The mechanism has been studied extensively ${ }^{7}$ and several ThDP-dependent lyases, such as pyruvate decarboxylases, branched-chain keto acid decarboxylase, benzoylformate decarboxylase, and benzaldehyde lyase, have been already characterized as powerful catalysts. ${ }^{8}$ As most of the wild type (wt) enzymes are $(R)$-selective, access to $(S)$ - $\alpha$-hydroxy ketones is limited. Structural basis for stereoselectivity has been investigated with the benzoylformate decarboxylase from Pseudomonas putida, which shows (S)-selectivity in the carboligation of benzaldehyde and acetaldehyde. ${ }^{9,10}$ The study revealed a

\footnotetext{
${ }^{a}$ IBG-1: Biotechnology, Forschungszentrum Jülich GmbH, Leo-Brandt-Str. 1, 52425 Jülich, Germany. E-mail: ma.pohl@fz-juelich.de; Fax: +49-(0)2461-61-3870; Tel: +49-(0)2461-61-4388

${ }^{b}$ Institute of Pharmaceutical Sciences, Albert-Ludwigs-Universität Freiburg, Albertstr. 25, 79104 Freiburg, Germany

${ }^{c}$ Institute of Technical Biochemistry, University of Stuttgart, Allmandring 31, 70569 Stuttgart, Germany

$\dagger$ Electronic supplementary information (ESI) available: Materials and experimental procedures, details of structural investigation of $E c$ MenD. See DOI: $10.1039 / \mathrm{c} 3 \mathrm{cc} 38607 \mathrm{~d}$
}

structural element called "S-pocket", which allows an antiparallel arrangement of donor and acceptor substrates, the prerequisite for $(S)$-selectivity. ${ }^{11}$ S-pockets are present in most of the $(R)$-selective enzymes, however, not accessible to acceptor substrates due to large amino acid side chains. ${ }^{12,13}$

The ThDP-dependent enzyme 2-succinyl-5-enolpyruvyl-6hydroxy-3-cyclohexene-1-carboxylate synthase from Escherichia coli $(E c \mathrm{MenD})$ catalyzes the second step in the biosynthesis of menaquinones. ${ }^{14}$ The carboligation potential of EcMenD has recently been characterized concerning substrate diversity and stereoselectivity. ${ }^{15,16}$ EcMenD uses $\alpha$-ketoglutarate (1) as the physiological donor, which is extraordinary among ThDPdependent enzymes. This enables selective C4 chain elongation with a terminal carboxyl group. EcMenD accepts a broad range of aldehydes as acceptors. Carboligation of $\mathbf{1}$ (upon decarboxylation) with different aromatic aldehydes gives $\alpha$-hydroxy ketones with high enantiomeric excesses (ee) of $>93 \%(R) .{ }^{16}$ Here, we report the first rationally designed $E c$ MenD variants for the syntheses of functionalized $(S)$ - $\alpha$-hydroxy ketones starting from $\mathbf{1}$ and differently substituted benzaldehyde derivatives 2 .

We combined rational protein engineering with substrate engineering to get access to functionalized $(S)$ - $\alpha$-hydroxy ketones. Important residues of the S-pocket were identified based on the crystal structure of $E c$ MenD (2JLC). ${ }^{17}$ Using docking studies (see ESI $\dagger$ ) with benzaldehyde (2a), two residues were deduced to be crucial for stereoselectivity: I474 and F475 prevent the antiparallel arrangement of $2 \mathrm{a}$ prior to $\mathrm{C}-\mathrm{C}$-bond formation. This explains the high $(R)$-selectivity of $99 \%$ ee of the wt enzyme in the carboligation reaction with 1 (Scheme 1A). Hence, in order to gain sufficient space for the phenyl ring of 2a, both I474 and F475 were mutated to glycine and alanine, respectively.

Four variants were prepared: I474G/F475G, I474G/F475A, I474A/F475G, and I474A/F475A. In all cases, the formation of $(S)$-5-hydroxy-4-oxo-5-phenylpentanoate (3a) was observed. Whereas variants $\mathrm{I} 474 \mathrm{G} / \mathrm{F} 475 \mathrm{G}$ and $\mathrm{I} 474 \mathrm{G} / \mathrm{F} 475 \mathrm{~A}$ showed only low selectivity for the formation of $(S)-3$ a (ee $34 \%$ and ee $27 \%$ ), the variants $\mathrm{I} 474 \mathrm{~A} / \mathrm{F} 475 \mathrm{~A}$ and $\mathrm{I} 474 \mathrm{~A} / \mathrm{F} 475 \mathrm{G}$ revealed higher $(S)$-selectivities of $66 \%$ ee and $75 \%$ ee, respectively. Thus, the S-pocket could be opened such that 2 a was able to arrange 


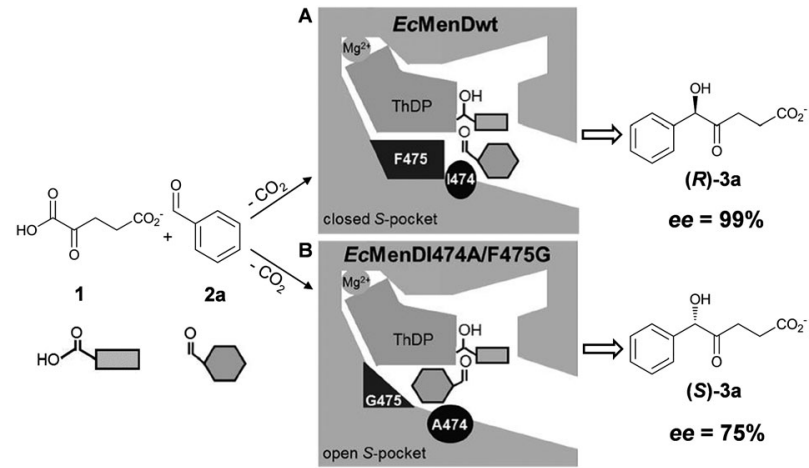

Scheme 1 Inversion of the stereoselectivity of wt EcMenD by structure-based design of the active site.

predominantly in an antiparallel orientation relative to the ThDP-bound donor aldehyde (Scheme 1B). Consequently, the results support the previously developed S-pocket concept. ${ }^{11,12}$ Besides accessibility of the S-pocket, optimal stabilization of the acceptor 2a is crucial for high stereoselectivity. Best stabilization of antiparallely oriented $2 \mathbf{a}$ seemed to be achieved in I474A/F475G. However, the catalytic activity, which may be estimated from the conversions of the $E c M e n D$ variants, was lower compared to the wt enzyme (Table 1). Whereas I474G/ F475A and I474A/F475A still showed a good conversion of $67 \%$ and $68 \%$, respectively, variants $\mathrm{I} 474 \mathrm{G} / \mathrm{F} 475 \mathrm{G}$ and I474A/F475G revealed only $26 \%$ and $15 \%$ conversion after $24 \mathrm{~h}$ under the tested conditions. Mutation of two adjacent amino acids in the active site might destabilize the binding of the substrate, in which the introduction of glycine at position 475 seemed to have a significant influence on the conversion.

The full catalytic potential of the three best $(S)$-selective EcMenD variants I474G/F475G, I474A/F475G, and I474A/F475A was explored in the next step. Various ortho-, meta-, and para-substituted benzaldehydes were tested beginning with fluoro- and chlorobenzaldehydes (2b-g). As expected, stereoselectivity was affected with all substrates compared to the high $(R)$-selectivity of $E c$ MenDwt (ee > 93\%, Table 1). EcMenD variants showed the following trends: all tested ortho- and para-substituted benzaldehyde derivatives resulted in a higher amount of the $(R)$-enantiomer compared to $\mathbf{2 a}$, while the metasubstituted benzaldehydes led to higher $(S)$-selectivity relative to 2a. Under non-optimized experimental conditions lowest conversions of $<24 \%$ were observed for para-substituted derivatives $2 \mathbf{d}$ and $\mathbf{2 g}$, which might be a consequence of weak substrate stabilization in the active site concomitant with low conversion rates. Compared to the para-substituted benzaldehydes higher conversions of 31-76\% were observed with orthosubstituted derivatives. As in both cases the $(R)$-enantiomers are predominantly formed, a sub-optimal stabilization of orthoand para-substituted benzaldehydes in the S-pockets of the three tested $E c$ MenD variants can be deduced. Remarkable results were obtained with meta-substituted benzaldehydes as acceptors: $(S)$-selectivity as well as conversion could be enhanced significantly with all variants compared to benzaldehyde $2 \mathbf{a}$ as the acceptor. Employing $2 \mathbf{c}$ and especially $\mathbf{2 f}$ stereoselectivities of $59-89 \%$ ee $(S)$ and conversions of $43-94 \%$ were obtained. Consequently, the nature of the substrate plays an important role. As meta-substituted benzaldehyde derivatives seem to be highly beneficial for (S)-selective carboligation using $E c$ MenD variants, $\mathbf{2 h}-\mathbf{2} \mathbf{j}$ were also tested in the carboligation with $\mathbf{1}$. Whereas substrate $2 \mathbf{j}$ was also highly $(S)$-selectively transformed with an ee of $78-93 \%$, the most striking result was obtained with $2 \mathbf{h}$ and $2 \mathbf{i}$. With these substrates an almost complete inversion of stereoselectivity was possible, connected with high conversions of $>86 \%$ under the tested conditions. For instance, I474A/F475A catalyzes the formation of $3 \mathbf{h}$ with complete conversion and an ee of $95 \%(S)$. In order to examine

Table 1 Carboligation of $\alpha$-ketoglutarate (1) and differently substituted benzaldehydes (2) to functionalized chiral $\alpha$-hydroxy ketones (3) by EcMenDwt and variants ${ }^{a}$<smiles>O=C(O)CCC(=O)O</smiles>

1<smiles>[R9]c1cc(C=O)c([R6])c([R9])c1[2H]</smiles>

2a-k

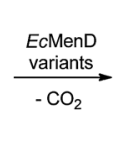

I474G/F475G

\begin{tabular}{|c|c|c|c|c|c|c|c|c|c|c|c|c|}
\hline Product & $\mathrm{R}_{2}$ & $\mathrm{R}_{3}$ & $\mathrm{R}_{4}$ & $\mathrm{R}_{5}$ & Conv. $^{b}(\%)$ & $\mathrm{ee}^{c}(\%)$ & Conv. $^{b}(\%)$ & $\mathrm{ee}^{c}(\%)$ & Conv. $^{b}(\%)$ & $\mathrm{ee}^{c}(\%)$ & Conv. $^{b}(\%)$ & $\mathrm{ee}^{c}(\%)$ \\
\hline $3 a$ & $\mathrm{H}$ & $\mathrm{H}$ & $\mathrm{H}$ & $\mathrm{H}$ & $>99$ & $>99(R)$ & 26 & $34(S)$ & 68 & $66(S)$ & 15 & $75(S)$ \\
\hline $3 c$ & $\mathrm{H}$ & $\mathrm{F}$ & $\mathrm{H}$ & $\mathrm{H}$ & $>99$ & $96(R)$ & 58 & $59(S)$ & 75 & $80(S)$ & 43 & $82(S)$ \\
\hline $3 d$ & $\mathrm{H}$ & $\mathrm{H}$ & $\mathrm{F}$ & $\mathrm{H}$ & $>99$ & $99(R)$ & 10 & $32(R)$ & 24 & $30(S)$ & 14 & $46(S)$ \\
\hline $3 e$ & $\mathrm{Cl}$ & $\mathrm{H}$ & $\mathrm{H}$ & $\mathrm{H}$ & 98 & $93(R)$ & 31 & $70(R)$ & 66 & $40(R)$ & 57 & $\leq 5$ \\
\hline $3 \mathbf{i}$ & $\mathrm{H}$ & I & $\mathrm{H}$ & $\mathrm{H}$ & $>99$ & $94(R)$ & $>99$ & $91(S)$ & 99 & $93(S)$ & 86 & $93(S)$ \\
\hline $3 \mathbf{j}$ & $\mathrm{H}$ & $\mathrm{OCH}_{3}$ & $\mathrm{H}$ & $\mathrm{H}$ & 99 & $>99(R)$ & 99 & $78(S)$ & 89 & $87(S)$ & 64 & $93(S)$ \\
\hline $3 \mathbf{k}$ & $\mathrm{H}$ & $\mathrm{OCH}_{3}$ & $\mathrm{H}$ & $\mathrm{OCH}_{3}$ & 99 & $98(R)$ & 99 & $85(S)$ & 98 & $96(S)$ & 83 & $96(S)$ \\
\hline
\end{tabular}

${ }^{a}$ Carboligation reaction was performed in $50 \mathrm{mM}$ potassium phosphate buffer, $\mathrm{pH}$ 8.0, $(2 \mathrm{mM} \mathrm{MgSO}, 0.1 \mathrm{mM}$ ThDP, and 5 vol\% MTBE) with 0.70 $\mathrm{mg}$ of the respective $E c$ MenD variant at $30{ }^{\circ} \mathrm{C}$ and $300 \mathrm{rpm}$ for $24 \mathrm{~h}$ using $50 \mathrm{mM} \alpha$-ketoglutarate (1) and 20 mM benzaldehyde derivatives (2a-k). ${ }^{b}$ Conversion was determined by GC-MS [DB-5MS Agilent] based on benzaldehyde consumption. ${ }^{c}$ Determined by chiral HPLC analysis using a Chiralpak IC, and Chiralcel OB and OD-H, respectively. The absolute configuration was determined by circular dichroism. 
the full potential of the S-pocket, 3,5-di-methoxybenzaldehyde (2k) was finally tested. The results obtained with variants $1474 \mathrm{~A} /$ F475G and I474A/F475A, which catalyze the formation of $(S)$-3k with an ee of $96 \%$ and conversions of $>83 \%$, demonstrate that even this bulky substrate was able to enter the S-pocket properly.

The designed S-pocket of the $E c M e n D$ variants seems to be tailored for meta-substituted benzaldehydes. High stereoselectivities as well as high conversions suggested good stabilization of the acceptor in the S-pocket. Furthermore, the parallel acceptor orientation, leading to the respective $(R)$-product, might be destabilized, too (Scheme 1). Reaction engineering might further improve stereoselectivities and conversions. To explain these results as well as the selectivities with ortho- and para-substituted substrates, structural studies with these $(S)$-selective EcMenD variants are currently underway. Together with molecular dynamics simulations of the binding states (parallel and antiparallel orientation of the acceptor), we want to get a deeper insight into EcMenD selectivity and carboligation activity. Furthermore, we want to explore the scope of $E c$ MenD catalysis with other acceptor substrates, e.g. aliphatic aldehydes.

In conclusion, we have rationally designed the first MenD variants as powerful biocatalysts for the $(S)$-selective synthesis of functionalized $\alpha$-hydroxy ketones starting from differently substituted benzaldehydes. Mutation of two amino acids in the active site could invert the stereoselectivity of the wt enzyme for most of the investigated substrates. Particularly the use of meta-substituted substrates resulted in high $(S)$-selectivities accompanied by good to excellent conversions. Therewith, we provide access to new, yet not reported (S)-5-hydroxy-4-oxo-5phenylpentanoate derivatives.

Financial support by the German Research Foundation (DFG) in the frame of the research group "Diversity of asymmetric thiamine catalysis" FOR1296 and partial funding by the research training group "BioNoCo" (GK1166) are gratefully acknowledged.

\section{Notes and references}

1 W. Adam, M. Lazarus, C. R. Saha-Möller and P. Schreier, Acc. Chem. Res., 1999, 32, 837.

2 P. Hoyos, J. V. Sinisterra, F. Molinari, A. R. Alcantara and P. D. de Maria, Acc. Chem. Res., 2010, 43, 288.

3 V. B. Shukla and P. R. Kulkarni, World J. Microbiol. Biotechnol., 2000, 16, 499.

4 J. Kulig, R. C. Simon, C. A. Rose, S. M. Husain, M. Hackh, S. Lüdecke, K. Zeitler, W. Kroutil, M. Pohl and D. Rother, Catal. Sci. Technol., 2012, 2, 1580.

5 D. Enders, O. Niemeier and A. Henseler, Chem. Rev., 2007, 107, 5606.

6 S. E. O'Toole, C. A. Rose, S. Gundala, K. Zeitler and S. J. Connon, J. Org. Chem., 2011, 76, 347.

7 F. Jordan, Nat. Prod. Rep., 2003, 20, 184.

8 M. Müller, D. Gocke and M. Pohl, FEBS J., 2009, 276, 2894.

9 R. Wilcocks and O. P. Ward, Biotechnol. Bioeng., 1992, 39, 1058.

10 H. Iding, T. Dünnwald, L. Greiner, A. Liese, M. Müller, P. Siegert, J. Grötzinger, A. S. Demir and M. Pohl, Chem.-Eur. J., 2000, 6, 1483.

11 D. Gocke, L. Walter, E. Gauchenova, G. Kolter, M. Knoll, C. L. Berthold, G. Schneider, J. Pleiss, M. Müller and M. Pohl, ChemBioChem, 2008, 9, 406.

12 D. Rother, G. Kolter, T. Gerhards, C. L. Berthold, E. Gauchenova, M. Knoll, J. Pleiss, M. Müller, G. Schneider and M. Pohl, ChemCatChem, 2011, 3, 1587.

13 M. Pohl, D. Gocke and M. Müller, in Handbook of Green Chemistry, Green Catalysis, Vol. 3, Biocatalysis, ed. P. T. Anastas, Wiley-VCH, Weinheim, 2008, vol. 2009, pp. 75-114.

14 M. Jiang, Y. Cao, Z.-F. Guo, M. Chen, X. Chen and Z. Guo, Biochemistry, 2007, 46, 10979.

15 J. Bongaerts, S. Esser, V. Lorbach, L. Al-Momani, M. A. Müller, D. Franke, C. Grondal, A. Kurutsch, R. Bujnicki, R. Takors, L. Raeven, M. Wubbolts, R. Bovenberg, M. Nieger, M. Schürmann, N. Trachtmann, S. Kozak, G. A. Sprenger and M. Müller, Angew. Chem., Int. Ed., 2011, 50, 7781.

16 A. Kurutsch, M. Richter, V. Brecht, G. A. Sprenger and M. Müller, J. Mol. Catal. B: Enzym., 2009, 61, 56.

17 A. Dawson, P. K. Fyfe and W. N. Hunter, J. Mol. Biol., 2008, 384, 1353. 